\title{
El Impacto de la infraestructura en el desarrollo económico
}

\author{
Gustavo Edgar Silva del Castillo \\ gsilvad@ucvvirtual.edu.pe \\ Universidad César Vallejo \\ Tarapoto-Perú \\ ORCID: 0000-0002-4437-9767
}

\section{José Manuel Delgado Bardales \\ jmdelgadob@ucvvirtual.edu.pe \\ Escuela de posgrado \\ Universidad César Vallejo \\ Tarapoto - Perú \\ ORCID: 0000-0001-6575-2759 \\ Scopus autor ID: 24070333700 \\ Código Renacyt: P0050554}

\section{RESUMEN}

La investigación caracterizó la incidencia que tiene el desarrollo de infraestructura con el desarrollo económico. La investigación fue no experimental básica y el diseño de estudio de revisión sistemática; las revisiones sistemáticas han sido realizadas de investigaciones científicas, las mismas que son consideradas como estudios originales primarios, siendo de importante ayuda para concentrar información relevante sobre el tema. Con respecto a la infraestructura, se ha podido identificar que existe una alta brecha de infraestructura, lo que impacta en la competitividad del país y limita el desarrollo económico, por consiguiente, el mejor mecanismo para reducir la pobreza y contribuir al desarrollo económico es con infraestructura, la que debe ser ejecutada por los tres niveles de gobierno, siendo los gobiernos locales los que ejecutan el mayor porcentaje del presupuesto destinado para este fin.

Palabras clave: Desarrollo urbano, gestión, crecimiento, inversión. 


\title{
The Impact of Infrastructure on Economic Development
}

\begin{abstract}
The research characterized the incidence that infrastructure development has with economic development. The research was non-experimental and the basic study design systematic review; The systematic reviews have been carried out of scientific investigations, which are considered as primary original studies, being of important help to concentrate relevant information on the subject. With regard to infrastructure, it has been possible to identify that there is a high infrastructure gap, which impacts the country's competitiveness and limits economic development, therefore, the best mechanism to reduce poverty and contribute to economic development is with infrastructure. , which must be executed by the three levels of government, with local governments executing the highest percentage of the budget allocated for this purpose.
\end{abstract}

Keywords: Urban development, management, growth, investment

Artículo recibido: 03 nov. 2020 Aceptado para publicación: 07 dic. 2020 Correspondencia: gsilvad@ucvvirtual.edu.pe Conflictos de Interés: Ninguna que declarar 


\section{INTRODUCCIÓN}

La necesidad de infraestructura adecuada para cubrir las necesidades de la población, es un problema a nivel mundial, que ha llevado a los líderes de distintas ciudades a buscar alternativas de solución ante esta situación, cabe precisar que no solamente es el hecho de diseñar y ejecutar la infraestructura, sino también medir el impacto económico que esta genera en la localidad, es por ello la relevancia del hecho de encontrar una solución integral. Este problema se ha presentado también en ciudades importantes de América Latina, como Bogotá y Medellín en Colombia, ciudades que buscaron la manera de solucionar este problema, lo que las llevó a la creación de una institución especializada en desarrollar proyectos de infraestructura, con la consecuente ejecución de los mismos, generando con ello integración de la población, atractivos turísticos y dinamismo económico. La inversión en infraestructura ha tenido impacto en el crecimiento económico de Colombia (Ortiz, 2019).

Sin embargo, la gestión municipal liderada por el alcalde es la encargada de la administración de los recursos con los que cuenta la municipalidad, así también el prestar los servicios públicos que le corresponde y realizar inversiones en obras de su competencia. Es importante incidir en ella específicamente en el desarrollo de infraestructura adecuada para la población, puesto que la inversión en infraestructura es un agente dinamizador de la economía y generador de puestos de trabajo. Al observar la inversión en infraestructura en los años anteriores, notamos que faltan obras de impacto que solucionen problemas y la celeridad para ejecutarlos, entre otros factores por la falta de un organismo especializado en el desarrollo de proyectos, con un equipo técnico y gestión independientes, que sean los encargados del diseño, ejecución y asesoría correspondiente. Cabe señalar que la brecha de infraestructura en el Perú supera los 159 mil millones de dólares, según la comisión de economía del Congreso de la República a enero del 2019, además el Perú se ubica en el puesto 85 de 137 países en el indicador de calidad de infraestructura del Índice de Competitividad Global 2017-2018 (Foro Económico Mundial 2018).

Además, existen experiencias relevantes en otras ciudades sobre este modelo de gestión, que han permitido el desarrollo de proyectos en infraestructura que han tenido impacto en la ciudadanía, generando nuevos espacios, fomentando el turismo y como consecuencia de ello, generando dinamismo económico. Cabe resaltar la importancia 
que tiene la provincia de San Martín dentro del circuito turístico nacional, es por tal razón que se necesita sentar las bases para generar la inversión en infraestructura y con ello dinamizar la economía local, además de la creación de puestos de trabajo. Es preciso señalar que la brecha de infraestructura en la región San Martín asciende a 8,022 millones de soles al 2018 y la ejecución de proyectos de infraestructura el 2016 fue de 220 millones de soles y 335 millones de soles el 2017 en el sector transporte vial, 102 millones de soles el 2016 y 161 millones de soles el 2017 en el sector educación, 135 millones de soles el 2016 y 248 millones de soles el 2017 en agua y saneamiento, 171 millones de soles el 2016 y 110 millones de soles el 2017 en salud, según el reporte de brecha de inversión en infraestructura (ESAN 2018).

\section{ESTRATEGIAS METODOLÓGICAS O MATERIALES Y MÉTODOS}

El tipo de investigación fue no experimental básica de revisión sistemática, las revisiones sistemáticas tratan de contestar una pregunta concreta, emplean una estrategia de búsqueda claramente especificada y unos criterios de inclusión de trabajos explícitos y rigurosos, lo que las hace altamente reproducibles. Además, siempre que las características de los estudios primarios lo permiten, se completan con una síntesis cuantitativa que recibe nombre de metanálisis (Molina, 2018). Es básica, no experimental, porque no se van a manipular las variables y es descriptiva dado que da a conocer las características del impacto económico.

Para la recolección de datos se ha utilizado una tabla de registro de datos y las fuentes se han tomado de los buscadores de la universidad César Vallejo, para tal efecto se realizó la búsqueda de artículos científicos con antigüedad no mayor a 5 años. Al realizar la búsqueda se consideraron ambas variables de investigación: Implementación del instituto de desarrollo urbano e impacto económico. Se han conseguido 10 artículos científicos, los cuales han sido seleccionados conforme al objetivo planteado, que busca identificar las características del impacto económico de la infraestructura.

La técnica de análisis fue en base a 10 artículos científicos que luego de ser analizados se han extraído los elementos considerados como más relevantes y posteriormente se han clasificado y ordenado para ser utilizados en el presente artículo. 


\section{RESULTADOS Y DISCUSIÓN}

\section{Resultados}

\section{DATOS DE LA PUBLICACIÓN}

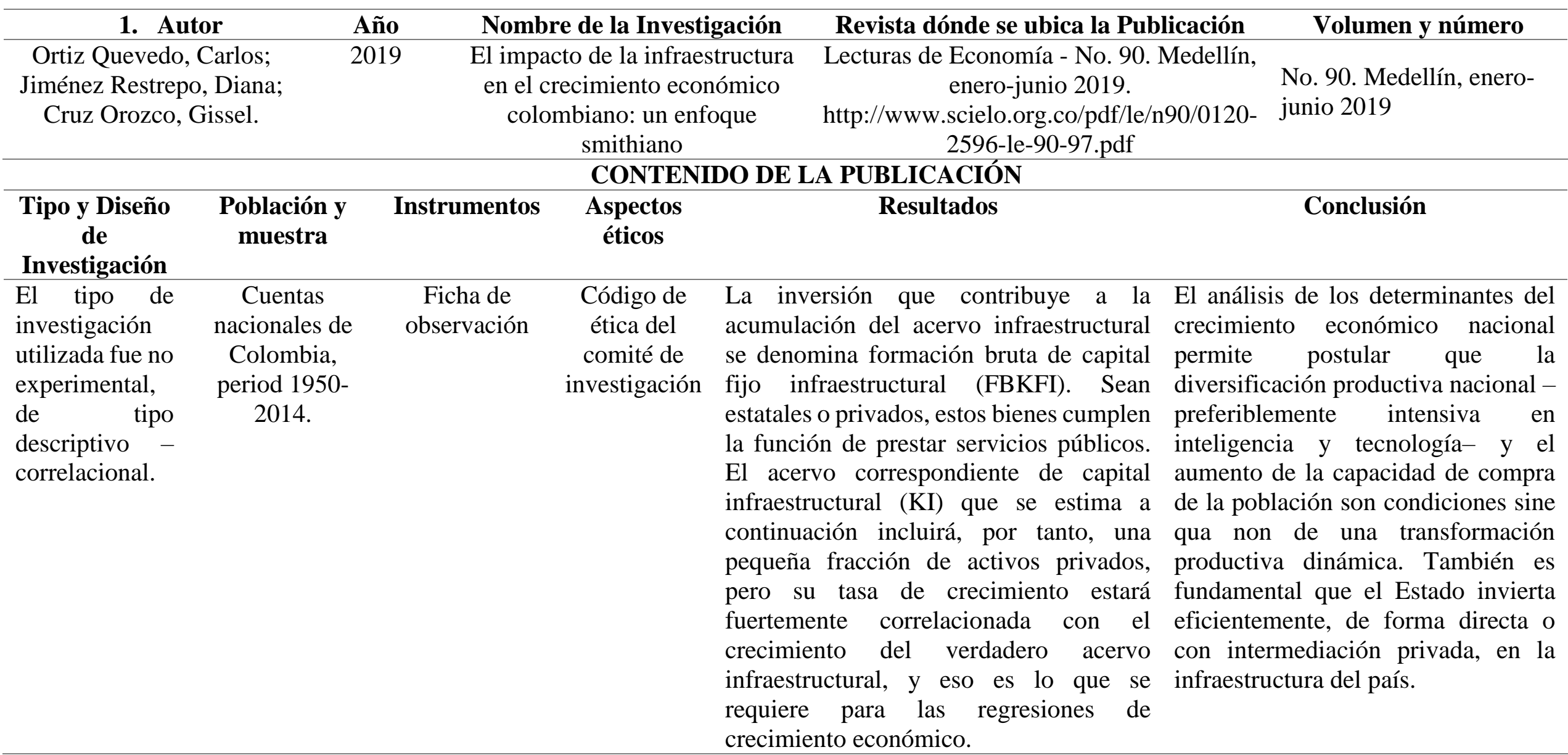




\begin{tabular}{|c|c|c|c|c|c|c|}
\hline \multirow{2}{*}{\multicolumn{2}{|c|}{$\begin{array}{c}\text { 2. Autor } \\
\text { Maraví, Gabriela; Matuk, } \\
\text { Diego; Chong, Mario }\end{array}$}} & \multirow{3}{*}{$\begin{array}{l}\text { Año } \\
2019\end{array}$} & de la Investigación & \multirow{2}{*}{\multicolumn{2}{|c|}{$\begin{array}{c}\text { Revista dónde se ubica la Publicación } \\
\text { Memoria Investigaciones en Ingeniería } \\
N^{\mathrm{a}} 17 \text {, Perú. }\end{array}$}} & \multirow{3}{*}{$\begin{array}{c}\text { Volumen y número } \\
\mathrm{N}^{\circ} .17,2019\end{array}$} \\
\hline & & & $\begin{array}{l}\text { la infraestructura e } \\
\text { aciones logísticas. }\end{array}$ & & & \\
\hline \multicolumn{5}{|c|}{ CONTENIDO DE LA PUBLICACIÓN } & & \\
\hline $\begin{array}{l}\text { Tipo y Diseño } \\
\text { de } \\
\text { Investigación }\end{array}$ & $\begin{array}{l}\text { Población y } \\
\text { muestra }\end{array}$ & Instrumentos & Aspectos éticos & Resultados & & Conclusión \\
\hline $\begin{array}{l}\text { El tipo de } \\
\text { nvestigación } \\
\text { es no } \\
\text { experimental, } \\
\text { diseño es } \\
\text { lescriptivo. }\end{array}$ & $\begin{array}{l}\text { Zona comercial } \\
\text { del distrito de } \\
\text { Lurigancho- } \\
\text { Chosica } \\
\text { superficie de } \\
236,47 \mathrm{~km} 2\end{array}$ & $\begin{array}{l}\text { Recolección de } \\
\text { información y } \\
\text { observación, a } \\
\text { través de revisión } \\
\text { documental y } \\
\text { fichas de } \\
\text { observación y } \\
\text { cálculo }\end{array}$ & $\begin{array}{l}\text { Código de ética } \\
\text { en investigación }\end{array}$ & $\begin{array}{l}\text { Todos los comercios del área } \\
\text { comercial carecen de una zona } \\
\text { de carga y descarga, además } \\
\text { de estacionamientos de los } \\
\text { locales comerciales. }\end{array}$ & $\begin{array}{l}\text { Uno de los } \\
\text { transporte y } \\
\text { carga y en } \\
\text { sistema donc } \\
\text { mercaderías, } \\
\text { los espaci } \\
\text { infracciones } \\
\text { públicas } \\
\text { contaminant }\end{array}$ & $\begin{array}{l}\text { sistemas relacionados con el } \\
\text { distribución es la gestión de } \\
\text { rega de mercancías; en un } \\
\text { e el mercado debe recibir las } \\
\text { y los transportistas deben usar } \\
\text { os públicos considerando } \\
\text { de tránsito, uso de las vías } \\
\text { generación de gases } \\
\text { s }\end{array}$ \\
\hline
\end{tabular}

\begin{tabular}{|c|c|c|c|c|c|c|}
\hline \multicolumn{2}{|c|}{ 3. Autor } & Año & Nomb & bre de la Investigación & Revista dónde se ubica la Publicación & Volumen y número \\
\hline \multicolumn{2}{|c|}{$\begin{array}{l}\text { Salazar, Inocente; Caro, } \\
\text { Nebenka; Zegarra, Estela. }\end{array}$} & 2016 & $\begin{array}{r}\text { Desem } \\
\text { desar } \\
\text { Municipali } \\
\text { Prado (H }\end{array}$ & $\begin{array}{l}\text { npeño de la gerencia de } \\
\text { rrollo económico de la } \\
\text { lidad provincial de Leoncio } \\
\text { (Huánuco) y el desarrollo } \\
\text { económico local. }\end{array}$ & Revista Investigación y Amazonía & 6(2): 11-19 2016 \\
\hline \multicolumn{7}{|c|}{ CONTENIDO DE LA PUBLICACIÓN } \\
\hline $\begin{array}{c}\text { Tipo y Diseño } \\
\text { de } \\
\text { Investigación }\end{array}$ & $\begin{array}{r}\text { Pobla } \\
\text { mue }\end{array}$ & & Instrumentos & Aspectos éticos & Resultados & Conclusión \\
\hline $\begin{array}{l}\text { El tipo de } \\
\text { investigación } \\
\text { fue no }\end{array}$ & $\begin{array}{r}\text { Las activ } \\
\text { ejecutada } \\
\text { Gerenc }\end{array}$ & & $\begin{array}{l}\text { Recolección } \\
\text { de } \\
\text { información y }\end{array}$ & $\begin{array}{l}\text { Código de } \\
\text { ética en } \\
\text { investigación }\end{array}$ & $\begin{array}{ll}\text { to de la actividad } & \text { Las acciones desa } \\
\text { egional, evidenciada } & \text { Gerencia de Desar } \\
\text { o Bruto Interno (PBI), } & \text { estarán contribuye }\end{array}$ & $\begin{array}{l}\text { olladas por la Sub } \\
\text { llo Empresarial, no } \\
\text { do en la percepción }\end{array}$ \\
\hline
\end{tabular}




\begin{tabular}{lcc}
\hline experimental & Desarrollo & observación, a \\
de enfoque & Económico & través de \\
cualitativo, el & (GDE) de la & revisión \\
diseño fue & Municipalidad & documental y \\
descriptivo. & $\begin{array}{c}\text { Provincial de } \\
\text { feoncio Prado de } \\
\text { (Huánuco) }\end{array}$ & $\begin{array}{c}\text { observación y } \\
\text { cálculo. }\end{array}$
\end{tabular}

\begin{abstract}
nos indica que la situación de desarrollo económico local de Tingo económica es positiva, el María, por parte de los pequeños y crecimiento es permanente y microempresarios, quizás existan otros sustentado; empero, la factores adicionales a los considerados contribución al PBI nacional ha ido en este estudio que influyen en sus decayendo para luego recuperarse percepciones.
\end{abstract} consistentemente (Figura 1) (23). La tendencia seguida nos hace sospechar que aun habiendo crecido localmente, en el contexto nacional hemos venido decayendo, o las demás regiones han crecido más. Ello explicaría por qué aún se mantiene una tasa de pobreza de $40 \%$ (24).

\begin{tabular}{ccccc} 
4. Autor & Año & Nombre de la Investigación & Revista dónde se ubica la Publicación & Volumen y número \\
\hline Tudela, Juan; Leos, Juan & 2017 & Estimación de beneficios & Revista Chapingo Serie Ciencias Forestales & Vol. XXIV, núm.2, \\
& & económicos por mejoras en & mayo-agosto 2018 \\
& & $\begin{array}{c}\text { los servicios de saneamiento } \\
\text { básico mediante } \\
\text { experimentos de elección. }\end{array}$ & \\
& & \\
\hline
\end{tabular}

\section{CONTENIDO DE LA PUBLICACIÓN}

\begin{tabular}{|c|c|c|c|c|c|}
\hline $\begin{array}{l}\text { Tipo y Diseño } \\
\text { de } \\
\text { Investigación }\end{array}$ & $\begin{array}{l}\text { Población y } \\
\text { muestra }\end{array}$ & Instrumentos & $\begin{array}{l}\text { Aspectos } \\
\text { éticos }\end{array}$ & Resultados & Conclusión \\
\hline $\begin{array}{l}\text { El tipo de } \\
\text { investigación } \\
\text { es no }\end{array}$ & $\begin{array}{c}392 \text { jefes de } \\
\text { familia }\end{array}$ & $\begin{array}{l}\text { La entrevista, } \\
\text { y la } \\
\text { observación }\end{array}$ & $\begin{array}{c}\text { Consentimiento } \\
\text { informado. }\end{array}$ & $\begin{array}{l}\text { Las características socioeconómicas de } \\
\text { los usuarios reflejan el efecto } \\
\text { interacción con las constantes }\end{array}$ & $\begin{array}{l}\text { Este estudio evidencia que el atributo } \\
\text { tratamiento de aguas residuales es más } \\
\text { valorado que los atributos provisión de }\end{array}$ \\
\hline
\end{tabular}




\section{experimental, el diseño es} descriptivo. de campo,

para lo que se

utilizó una

hoja de

registro específicas para cada alternativa. Tanto el nivel de educación (EDU) como el nivel de ingreso (ING) fueron altamente significativos; es decir, a mayor nivel educativo y mayores niveles de ingreso se percibe mayor utilidad indirecta por las mejoras en los servicios de saneamiento básico. agua y alcantarillado; por tanto, cualquier política orientada a mejorar los servicios de saneamiento básico en la ciudad de Puno debería estar enfocada en solucionar el tema de tratamiento de aguas residuales. La elección de alternativas de mejora en los servicios de saneamiento básico está fuertemente condicionada por el nivel educativo y el ingreso monetario mensual de los usuarios.

\begin{tabular}{|c|c|c|c|c|c|c|}
\hline \multirow{2}{*}{\multicolumn{2}{|c|}{$\begin{array}{c}\text { 5. Autor } \\
\text { Saelzer, Gerardo; Yaw, } \\
\text { Augustine; Hosni, Jilan; } \\
\text { Ruiz, Antonio. }\end{array}$}} & \multirow{2}{*}{$\begin{array}{l}\text { Año } \\
2019\end{array}$} & \multirow{2}{*}{\multicolumn{2}{|c|}{$\begin{array}{l}\text { Nombre de la Investigación } \\
\text { Desafíos de planificación } \\
\text { urbana en la definición de } \\
\text { valores patrimoniales en el } \\
\text { sur de Chile. }\end{array}$}} & \multirow{2}{*}{$\begin{array}{c}\text { Revista dónde se ubica la Publicación } \\
\text { Revista Urbano }{ }^{\circ} \text { } 40 . \\
\text { DOI: } \\
\text { https://doi.org/10.22320/07183607.2019.22.40.05 }\end{array}$} & \multirow{3}{*}{$\begin{array}{c}\text { Volumen y número } \\
\text { noviembre } 2019 \text { - abril } \\
2020 \text { pág. } 88-107\end{array}$} \\
\hline & & & & & & \\
\hline \multicolumn{6}{|c|}{ CONTENIDO DE LA PUBLICACIÓN } & \\
\hline $\begin{array}{c}\text { Tipo y Diseño } \\
\text { de } \\
\text { Investigación }\end{array}$ & $\begin{array}{r}\text { Pobl } \\
\text { mu }\end{array}$ & & Instrumentos & Aspectos éticos & Resultados & Conclusión \\
\hline $\begin{array}{l}\text { El tipo de } \\
\text { investigación } \\
\text { fue descriptiva, } \\
\text { el diseño fue } \\
\text { mixto. }\end{array}$ & $\begin{array}{r}\text { La po } \\
\text { mue } \\
\text { traba } \\
\text { datos } 1 \\
\text { y } \\
\text { secur }\end{array}$ & $\begin{array}{l}\text { ión } \\
\text { se } \\
\text { on } \\
\text { arios } \\
\text { s } \\
\text { ios. }\end{array}$ & $\begin{array}{l}\text { La entrevista, } \\
\text { y el análisis } \\
\text { documental. }\end{array}$ & $\begin{array}{l}\text { Código de ética } \\
\text { en investigación }\end{array}$ & $\begin{array}{ll}\text { La definición chilena de patrimonio } & \text { El estudio d } \\
\text { y sus valores sigue la misma } & \text { para registra } \\
\text { trayectoria de las definiciones sobre } & \text { marco instit } \\
\text { monumentos de ICOMOS y } & \text { comprensión } \\
\text { UNESCO como factores de valores } & \text { Las perspe } \\
\text { tangibles e intangibles. No obstante, } & \text { patrimonio } \\
\text { lo que es tangible e intangible no se } & \text { tienen que c } \\
\text { ha sido estipulado con plena } & \text { definición } \\
\text { claridad. Por ejemplo, los entornos } & \text { valores t }\end{array}$ & $\begin{array}{l}\text { caso ofreció oportunidades } \\
\text { aspectos no observados del } \\
\text { cional y regulatorio sobre la } \\
\text { de los sitios patrimoniales. } \\
\text { ctivas de definición del } \\
\text { en el marco legal nacional } \\
\text { nectarse con la percepción y } \\
\text { el espacio. Igualmente, los } \\
\text { angibles, intangibles y }\end{array}$ \\
\hline
\end{tabular}


se mencionan de manera ambigua en relación a aspectos como el estilo de construcción, materiales y técnicas. Estos no se combinan con el entorno y las definiciones, y no está claro si se trata de un producto orgánico de la comunidad o de la naturaleza (Montella, 2015; MINEDUC, 2017).

\begin{tabular}{rcc}
\hline 6. Autor & Año & Nombre de la Investigación \\
\hline Marsano, José. & 2016 & $\begin{array}{c}\text { El impacto económico del } \\
\text { turismo en el Perú 1990 - 2015 }\end{array}$
\end{tabular}
turismo en el Perú 1990 - 2015. ambientales deben identificarse a través del proceso de declaración de ZT y de acuerdo con la planificación territorial.
Revista dónde se ubica la Publicación
Revista turismo y patrimonio
Universidad de San Martín de Porres,
Perú. ISSN: 1680-9556 (Impresa)
ISSN: 2313-853X (Digital)

Volumen y número

\begin{tabular}{|c|c|c|c|}
\hline $\begin{array}{c}\text { Tipo y Diseño } \\
\text { de } \\
\text { Investigación }\end{array}$ & $\begin{array}{c}\text { Población y } \\
\text { muestra }\end{array}$ & Instrumentos & $\begin{array}{l}\text { CONTENIDO } \\
\text { Aspectos } \\
\text { éticos }\end{array}$ \\
\hline $\begin{array}{l}\text { El tipo de } \\
\text { estudio fue no } \\
\text { experimental, } \\
\text { con diseño } \\
\text { descriptivo - } \\
\text { correlacional. }\end{array}$ & $\begin{array}{c}\text { Información } \\
\text { cuantitativa del } \\
\text { Banco de Datos } \\
\text { Turísticos del } \\
\text { Perú (Badatur } \\
\text { Perú), del } \\
\text { Observatorio } \\
\text { Turístico del } \\
\text { Perú }\end{array}$ & $\begin{array}{l}\text { Recolección } \\
\text { de } \\
\text { información y } \\
\text { observación, a } \\
\text { través de } \\
\text { revisión } \\
\text { documental y } \\
\text { fichas de } \\
\text { observación y } \\
\text { cálculo. }\end{array}$ & $\begin{array}{c}\text { Código de ética } \\
\text { en } \\
\text { investigación. }\end{array}$ \\
\hline
\end{tabular}

Ciencia Latina Revista Científica Multidisciplinar, Ciudad de México, México. 
regiones de sus territorios en verdaderos paraísos turísticos, consiguiendo ventajas competitivas difíciles de superar.

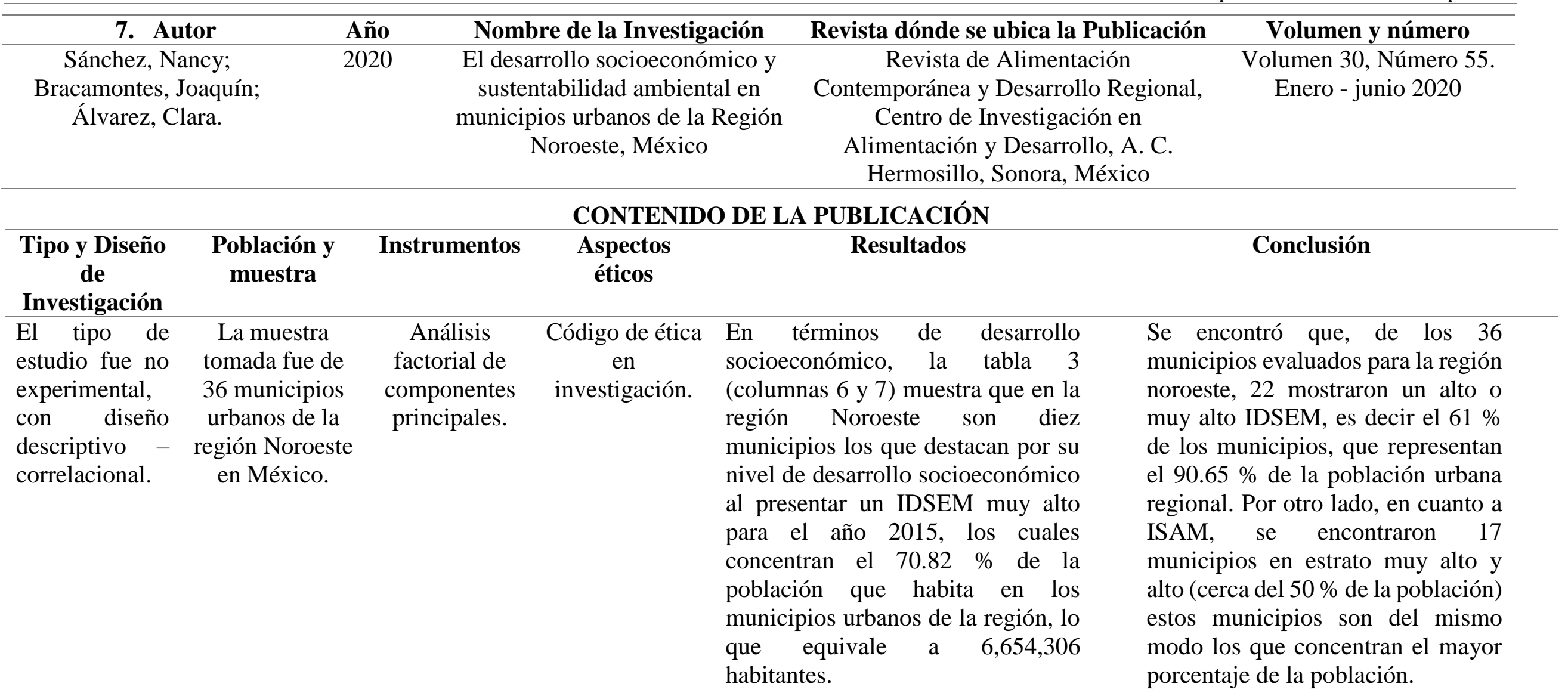




\section{CONTENIDO DE LA PUBLICACIÓN}

\begin{tabular}{|c|c|c|c|c|c|}
\hline \multicolumn{6}{|c|}{ Revista dónde se ubica la Publicación } \\
\hline \multicolumn{2}{|c|}{$\begin{array}{l}\text { Badii, M.H., Guillen, A; } \\
\text { Fernández, L.G; Abreu, } \\
\text { J.L. }\end{array}$} & \multicolumn{2}{|c|}{$\begin{array}{l}\text { La urbanización en relación con } \\
\text { el desarrollo sustentable. }\end{array}$} & $\begin{array}{l}\text { Daena: International Journal of Good } \\
\text { Conscience. ISSN 1870-557X. }\end{array}$ & 12(1)69-94. Marzo 2017 \\
\hline $\begin{array}{l}\text { Tipo y Diseño } \\
\text { de } \\
\text { Investigación }\end{array}$ & $\begin{array}{c}\text { Población y } \\
\text { muestra }\end{array}$ & Instrumentos & $\begin{array}{l}\text { Aspectos } \\
\text { éticos }\end{array}$ & Resultados & Conclusión \\
\hline $\begin{array}{l}\text { El tipo de } \\
\text { estudio fue no } \\
\text { experimental, } \\
\text { se tomó como } \\
\text { diseño el } \\
\text { descriptive. }\end{array}$ & $\begin{array}{l}\text { La población } \\
\text { muestral se } \\
\text { trabajó con } \\
\text { datos primarios } \\
\text { y datos } \\
\text { secundarios. }\end{array}$ & $\begin{array}{l}\text { Recolección } \\
\text { de } \\
\text { información y } \\
\text { observación, a } \\
\text { través de } \\
\text { revisión } \\
\text { documental. }\end{array}$ & $\begin{array}{ll}\text { Código de } & \text { Pese a q } \\
\text { ética } & \text { en filóso } \\
\text { investigación } & \text { algo } \\
& \text { medioar } \\
& \text { sería e } \\
& \text { cuando } \\
& \text { sustenta } \\
& \text { formal s } \\
& \text { efectos } \\
& \text { modelo } \\
& \text { la Revo } \\
& \text { aún más }\end{array}$ & $\begin{array}{l}\text { e algunos autores, científicos } \\
\text { s refirieron en algún punto } \\
\text { lativo al cuidado del } \\
\text { biente o su salvaguarda, no } \\
\text { la época contemporánea } \\
\text { el concepto de desarrollo } \\
\text { le, emergiera de manera } \\
\text { como respuesta natural a los } \\
\text { rovocados por el erróneo } \\
\text { e desarrollo adoptado desde } \\
\text { ción Industrial y potenciado } \\
\text { en las últimas décadas. }\end{array}$ & $\begin{array}{l}\text { os colocar de nueva cuenta } \\
\text { mbre como centro del } \\
\text { llo urbano en las ciudades y } \\
\text { ciudades a escala humana, } \\
\text { s, pero completamente } \\
\text { as a un desarrollo sostenible } \\
\text { permita la conservación, } \\
\text { ión regeneración y } \\
\text { ación del medio ambiente } \\
\text { y natural. }\end{array}$ \\
\hline 9. Au & & Noml & re de la Investigación & Revista dónde se ubica la Publicación & Volumen y número \\
\hline $\begin{array}{r}\text { Correa, Felipe } \\
\text { Marco. }\end{array}$ & Dini, & $\begin{array}{r}\mathrm{Pc} \\
\mathrm{ec} \\
\text { munici } \\
\text { all }\end{array}$ & $\begin{array}{l}\text { íticas de desarrollo } \\
\text { nómico local en las } \\
\text { alidades de Chile: más } \\
\text { del asistencialismo. }\end{array}$ & Revista de la CEPAL. & $\mathrm{N}^{\circ} 127 \cdot$ abril de 2019 \\
\hline
\end{tabular}




\section{CONTENIDO DE LA PUBLICACIÓN}

\begin{tabular}{|c|c|c|c|c|c|}
\hline $\begin{array}{l}\text { Tipo y Diseño de } \\
\text { Investigación }\end{array}$ & $\begin{array}{c}\text { Población y } \\
\text { muestra }\end{array}$ & Instrumentos & Aspectos éticos & Resultados & Conclusión \\
\hline $\begin{array}{l}\text { El tipo de estudio } \\
\text { fue no } \\
\text { experimental, se } \\
\text { tomó como diseño } \\
\text { el descriptivo. }\end{array}$ & $\begin{array}{l}\text { La población } \\
\text { muestral lo } \\
\text { conformaron los } \\
\text { Planes de } \\
\text { Desarrollo } \\
\text { Comunal } \\
\text { (PLADECO). }\end{array}$ & $\begin{array}{c}\text { Lectura y } \\
\text { sistematización } \\
\text { de las políticas } \\
\text { de desarrollo } \\
\text { económico } \\
\text { local propuestas } \\
\text { por las } \\
\text { municipalidades } \\
\text { de Chile. }\end{array}$ & $\begin{array}{l}\text { Código de ética } \\
\text { en } \\
\text { investigación. }\end{array}$ & $\begin{array}{l}\text { La categoría de } \\
\text { emprendimiento se encuentra } \\
\text { presente en el } 72 \% \text { de las } \\
\text { municipalidades y conforma, } \\
\text { después de la de capacitación, } \\
\text { el área de intervención de la } \\
\text { política de desarrollo } \\
\text { económico local más } \\
\text { extendida. Las políticas de } \\
\text { fomento del emprendimiento } \\
\text { comprenden las incubadoras } \\
\text { de negocios, el asesoramiento } \\
\text { para la postulación a fondos } \\
\text { de fomento productivo } \\
\text { públicos y privados. }\end{array}$ & $\begin{array}{l}\text { De las } 40 \text { categorías de política } \\
\text { identificadas, las municipalidades } \\
\text { consultadas rescatan en promedio } 16 \text {, es } \\
\text { decir, un } 40 \% \text { de las posibilidades de } \\
\text { política existentes. Por otra parte, la } \\
\text { presencia de estas } 40 \text { categorías da } \\
\text { cuenta de la posibilidad de trascender la } \\
\text { concepción asistencialista de la política } \\
\text { de desarrollo económico local, que en la } \\
\text { práctica se reduce a prestar ayuda } \\
\text { focalizada a personas desempleadas } \\
\text { mediante talleres, capacitaciones. }\end{array}$ \\
\hline
\end{tabular}

\begin{tabular}{ccccc}
\hline 10. Autor & Año & Nombre de la Investigación & Revista dónde se ubica la Publicación & Volumen y número \\
\hline Álvarez, Gustavo; & 2018 & El sector turístico, sus políticas y & Revista Dilemas Contemporáneos: & Año: VI Número: 1 \\
Paredes, Ángela; Chávez, & & su rol en el desarrollo social de & Educación, Política y Valores. & Artículo no.:67 \\
Lila; Velastegui, José. & & los países del Tercer Mundo. & Período: 1ro de \\
& & & septiembre al 31 de \\
& & & & diciembre del 2018 \\
\hline
\end{tabular}


CONTENIDO DE LA PUBLICACIÓN

\begin{tabular}{|c|c|c|c|c|c|}
\hline $\begin{array}{c}\text { Tipo y Diseño } \\
\text { de } \\
\text { Investigación }\end{array}$ & $\begin{array}{c}\text { Población y } \\
\text { muestra }\end{array}$ & Instrumentos & $\begin{array}{l}\text { Aspectos } \\
\text { éticos }\end{array}$ & Resultados & Conclusión \\
\hline $\begin{array}{l}\text { El tipo de } \\
\text { estudio fue no } \\
\text { experimental, } \\
\text { se tomó como } \\
\text { diseño el } \\
\text { descriptivo }\end{array}$ & $\begin{array}{l}\text { La población } \\
\text { muestral lo } \\
\text { conformaron los } \\
\text { documentos } \\
\text { fuente. }\end{array}$ & $\begin{array}{l}\text { Recolección } \\
\text { de } \\
\text { información y } \\
\text { observación, a } \\
\text { través de } \\
\text { revisión } \\
\text { documental. }\end{array}$ & $\begin{array}{l}\text { Código de } \\
\text { ética en } \\
\text { investigación. }\end{array}$ & $\begin{array}{l}\text { La actividad turística por la } \\
\text { masificación de los destinos } \\
\text { en países del Tercer Mundo } \\
\text { debería } \\
\text { producir el desarrollo y } \\
\text { crecimiento de las regiones } \\
\text { involucradas a partir del } \\
\text { turismo, de forma } \\
\text { directa o indirecta; no } \\
\text { obstante, esta no será la } \\
\text { única actividad de la que se } \\
\text { sustenten los destinos en } \\
\text { los que se desarrolle el } \\
\text { sector }\end{array}$ & $\begin{array}{l}\begin{array}{l}\text { El sector turístico requiere de una } \\
\text { infraestructura especial, }\end{array} \\
\text { implementación ocurre paralelamente a la } \\
\text { transformación del espacio, influyendo a su } \\
\text { vez en la sociedad local y su cultura. }\end{array}$ \\
\hline
\end{tabular}




\section{DISCUSIÓN}

Luego de la revisión sistemática de los diferentes artículos considerados, se observa que el 100\% son de América latina y el Caribe, donde sobresale la participación de México con el $40 \%$, seguido de Perú con el 30\%, Chile 20\% y Colombia $10 \%$ respectivamente. Respecto a los diseños y tipos de estudio, el 100\% de ellos son descriptivos.

Con respecto al impacto de la infraestructura en el crecimiento económico, Ortiz, C.; Jiménez, D.; Cruz, G.; establecen que la inversión que contribuye al acervo infraestructural es denominada formación bruta de capital fijo infraestructural, la misma que puede estar compuesta por capital público o privado, los cuales tienen por finalidad brindar servicios públicos. La tasa de crecimiento de la porción de activo privado dentro del acervo de capital infraestructural, estará fuertemente correlacionada con el crecimiento del acervo infraestructural, lo que a su vez se requiere para las regresiones de crecimiento económico. Por su parte Maraví, G; Matuk, D; Chong, M; establecen que todos los establecimientos comerciales de la zona de estudio, carecen de una zona de carga y descarga, adicional a ello, carecen de estacionamientos en los locales comerciales. También Tudela, Juan; Leos, Juan; fundamentan que, de acuerdo a las características socioeconómicas de los usuarios de servicios de saneamiento básico, como mayor nivel educativo y mayor nivel de ingresos, perciben mayor utilidad en las mejoras de la infraestructura de los servicios de saneamiento básico.

Además, Marsano, J; estabelece que el primer efecto macroeconómico positivo que brinda el turismo a la economía, es el incremento del ingreso nacional, cabe mencionar que el turismo tiene una participación del 3.75\% del PBI, siendo un importante generador de puestos de trabajo. Adicionalmente, Álvarez, G; Paredes, Á.; Chávez, L; Velastegui, J; establecen que la actividad turística debería producir desarrollo y crecimiento de las regiones involucradas, dado a la masificación de los destinos turísticos con los que cuentan.

\section{CONCLUSIÓN O CONSIDERACIONES FINALES}

El desarrollo de infraestructura es un agente dinamizador de la economía, puesto que dinamiza al sector construcción, que emplea abundante mano de obra, además es la locomotora que impulsa a otros sectores de la economía, como la producción de cemento y ferreterías que proveen los materiales requeridos en está actividad, por lo que es fuente generadora de trabajo y dinamizadora de la economia, pero además con la infraestructura 
puesta al servicio de la población, permite la integración de los pueblos, mejorando el acceso y reduciendo los costos logísticos.

El acervo de infraestructura del país no solamente está compuesto por la infraestructura desarrollada por el Estado, sino también por la inversión realizada por el sector privado, lo cual contribuye significativamente a dotar de infraestructura necesaria para la ciudadanía, lo que redundará en benefícios económicos para la población.

Las actividades de transporte de carga y descarga de mercancias, deben contar con la infraestructura necesaria para realizar sus operaciones logísticas, tomando en cuenta que se requiere de espacios públicos en las zonas comerciales que les permitan desarrollar sus atividades sin generar congestión en la zona, lo que impacta en la economía del sector.

Dentro de la infraestructura necesaria el saneamiento básico es importante, y que el atributo de tratamento de aguas residuales se valore más que el abastecimento de agua y alcantarillad. Además, que la mejora de los servicios de saneamento básico está condicionada por el nível educativo y nivel de ingresos de los usuarios.

Hay destinos turísticos que aprovechan su herencia cultural y patrimonial, pero también hay otros destinos turísticos que potencian su geografía relacionado con el turismo recreacional y de aventura, que viene ganando terreno y dinamiza la economía local, pero para ponerlos en valor, se requiere de la infraestructura adecuada para aceder a ellas.

Las actividades económicas vinculadas al turismo son ambientalmente sustentables y económicamente rentables, en vista que dinamiza la economía local, generando puestos de trabajo directos e indirectos, pero requiere de infraestructura especial para se desarrolló, lo que a su vez influye en positivamente en la sociedad local y su cultura.

\section{LISTA DE REFERENCIAS}

Álvarez, G.; Paredes, Á.; Chávez, L.; y Velasteguí, J. (2018). El sector turístico, sus políticas y su rol en el desarrollo social de los países del Tercer Mundo. (Spanish). Dilemas Contemporáneos: Educación, Política y Valores, 6(1), 118.

Correa, F.; y Dini, M. (2019). Políticas de desarrollo económico local en las municipalidades de Chile: más allá del asistencialismo. Revista de La CEPAL, 127, 55-73. https://doi.org/10.18356/e6cf151c-es.

Maraví, G.; Matuk, D.; Chong, M. (2019). Impacto de la infraestructura en las operaciones logísticas. Me moria Investigaciones en Ingeniería $\mathrm{N}^{\mathrm{a}} 17$. 
Marsano, J. (2016). El Impacto Económico Del Turismo en El Perú 1990 2015. Revista Turismo y Patrimonio, 10, 155-168.

Medrano, O. (2020). Ciudades sobrecargadas: la sobreexplotación de recursos como limitante del desarrollo sustentable. Antípoda, 39, 3-12. https://doi.org/10.7440/antipoda39.2020.01.

Ortiz, C.; Jiménez, D.; y Cruz, G. (2019). El impacto de la infraestructura en el crecimiento económico colombiano: un enfoque smithiano. Lecturas de Economía, 90, 97-126. https://doi.org/10.17533/udea.le.n90a04

Saelzer, G.; Yaw, A.; Hosni, J.; \& Tagle, A. R. (2019). Desafíos De Planificación Urbana en La Definición De Valores Patrimoniales en El Sur De Chile: Un Estudio De Caso De Valdivia: Una Ciudad De Madera en El Sur De Chile. Urbano, 22(40), 88-107. https://doi.org/10.22320/07183607.2019.22.40.05

Salazar, I.; Caro, N.; y Zegarra, E. (2019). Desempeño De La Gerencia De Desarrollo Económico De La Municipalidad Provincial De Leoncio Prado (Huánuco) Y El Desarrollo Económico Local.

Sánchez-Duarte, N.; Bracamontes-Nevárez, J.; y Álvarez-Chávez, C. (2020). El desarrollo socioeconómico y sustentabilidad ambiental en municipios urbanos de la Región Noroeste, México. Estudios Sociales: Revista de Alimentación Contemporánea y Desarrollo Regional, 30(55), 1-33. https://doi.org/10.24836/es.v30i55.868.

Tudela-Mamani, J.; y Leos-Rodríguez, J. (2018). Estimation of economic benefits due to improvements in basic sanitation services through choice experiments. Revista Chapingo Serie Ciencias Forestales, 24(2), 237-250. https://doi.org/10.5154/r.rchscfa.2017.05.037 